Article

\title{
Preparation and Characterization of Bioplastic-Based Green Renewable Composites from Tapioca with Acetyl Tributyl Citrate as a Plasticizer
}

Chi-Hui Tsou ${ }^{1,2,3, *}$, Maw-Cherng Suen ${ }^{4}$, Wei-Hua Yao ${ }^{3}$, Jen-Taut Yeh ${ }^{5}$, Chin-San Wu ${ }^{6}$, Chih-Yuan Tsou ${ }^{1}$, Shih-Hsuan Chiu ${ }^{1}$, Jui-Chin Chen ${ }^{3}$, Ruo Yao Wang ${ }^{3}$, Shang-Ming Lin ${ }^{3}$, Wei-Song Hung ${ }^{2, *}$, Manuel De Guzman ${ }^{2}$, Chien-Chieh Hu ${ }^{2}$ and Kueir-Rarn Lee ${ }^{2}$

1 Department of Materials Science and Engineering, National Taiwan University of Science and Technology, No. 43, Sec. 4, Keelung Rd., Da'an Dist., Taipei 10607, Taiwan;

E-Mails: keymykimo@gmail.com (C.-Y.T.); schiu@mail.ntust.edu.tw (S.-H.C.)

2 Research and Development Center for Membrane Technology, Department of Chemical Engineering, Chung Yuan University, Chung-Li 32023, Taiwan; E-Mails: maweidegz@gmail.com (M.D.G.); cchu@cycu.edu.tw (C.-C.H.); krlee@cycu.edu.tw (K.-R.L.)

3 Department of Materials and Textiles, Oriental Institute of Technology, Pan-Chiao 22064, Taiwan; E-Mails: angelayao@mail.oit.edu.tw (W.-H.Y.); fc011@mail.oit.edu.tw (J.-C.C.); steven5202001@yahoo.com.tw (R.Y.W.); fc013@mail.oit.edu.tw (S.-M.L.)

4 Department of Creative Fashion Design, Taoyuan Innovation Institute of Technology, Jhongli 32091, Taiwan; E-Mail: sun@tiit.edu.tw

5 Department of Chemical and Biochemical Engineering, Kao Yuan University, Kaohsiung County 82151, Taiwan; E-Mail: jyeh@mail.ntust.edu.tw

6 Faculty of Materials Science and Engineering, Hubei University, Wuhan 430062, China; E-Mail: cws1222@cc.kyu.edu.tw

* Authors to whom correspondence should be addressed;

E-Mails: mayko0301@hotmail.com (C.-H.T.); wshung@cycu.edu.tw (W.-S.H.);

Tel.: +886-3-2654190 (C.-H.T. \& W.-S.H.); Fax: +886-3-2654198 (C.-H.T. \& W.-S.H.).

Received: 9 June 2014; in revised form: 25 July 2014 / Accepted: 29 July 2014 /

Published: 4 August 2014

Abstract: Granular tapioca was thermally blended with poly(lactic acid) (PLA). All blends were prepared using a plasti-corder and characterized for tensile properties, thermal properties and morphology. Scanning electron micrographs showed that phase separation occurred, leading to poor tensile properties. Therefore, methylenediphenyl diisocyanate (MDI) was used as an interfacial compatibilizer to improve the mechanical properties of 
PLA/tapioca blends. The addition of MDI could improve the tensile strength of the blend with $60 \mathrm{wt} \%$ tapioca, from 19.8 to $42.6 \mathrm{MPa}$. In addition, because PLA lacked toughness, acetyl tributyl citrate (ATBC) was added as a plasticizer to improve the ductility of PLA. A significant decrease in the melting point and glass-transition temperature was observed on the basis of differential scanning calorimetry, which indicated that the PLA structure was not dense after ATBC was added. As such, the brittleness was improved, and the elongation at break was extended to several hundred percent. Therefore, mixing ATBC with PLA/tapioca/MDI blends did exhibit the effect of plasticization and biodegradation. The results also revealed that excessive plasticizer would cause the migration of ATBC and decrease the tensile properties.

Keywords: biodegradable; poly(lactic acid) (PLA); tapioca; methylenediphenyl diisocyanate (MDI); acetyl tributyl citrate (ATBC)

\section{Introduction}

Poly(lactic acid) (PLA) resins are well-known biodegradable, linear aliphatic thermoplastics, which can be produced from renewable resources [1,2]. They are one of the most promising polymers of their family [3] and are highly accepted as biomedical materials, because of their biocompatibility and good mechanical properties [4,5]. However, their brittleness, slow crystallization and being easily hydrolyzed limit their usage in many applications. In fact, it is difficult to use them for film blowing or extrusion, unless their moisture content and processing conditions are carefully controlled. Moreover, their price competitiveness in the biodegradable plastic market is an essential attribute that cannot be ignored. The most effective approach to reduce the capital cost of PLA is to use fillers. Cost-effective reinforcements are organic renewable resources [6], flax [7-9], sisal [10], lyocell [11], short abaca [12], jute [13], bamboo [14], paper pulp [15,16], pineapple [17], Cordenka [18], microcrystalline cellulose [19], and kenaf [20]. Starch is attractive because of its low cost, renewability, biodegradability, low density and non-abrasiveness. A lot of studies on the blending of PLA/starch [21-30], such as wheat starch [21,24,30], corn starch [26,27,29,31] and cassava starch [23], have been researched. Tapioca was used as a filler in [32], because it is cheap, and fewer reports compared it with other starches. However, the poor interfacial adhesion between the filler and the polymer generally leads to composites with worse mechanical properties. Surface and bulk modifications of the filler and/or matrix are necessary to increase the interfacial compatibility between the hydrophilic filler and the hydrophobic PLA matrix. Some studies used methylenediphenyl diisocyanate (MDI) as a compatibilizer to improve the compatibility between PLA and starch [21,30] or between PLA and rice husk [33]. These biopolymers are successfully prepared with starch or rice husk blends using MDI as a coupling agent. Copolymerization or blending PLA with other polymers [34-43] or compounds (e.g., plasticizers) [44-49] was proven to be a feasible way to improve its processability in film products for extrusion and/or film blowing. In this study, tapioca was used as a filler to reduce the cost of PLA products; MDI was used as a coupling agent to enhance the interfacial compatibility between PLA and tapioca; and ATBC was used as a plasticizer to improve the processability, flexibility and ductility of glassy PLA/tapioca composites. 
The result of this study could provide a database useful for the design and manufacture of biodegradable materials.

\section{Results and Discussion}

\subsection{Tensile Property}

The tensile strength $\left(\sigma_{\mathrm{f}}\right)$ and elongation at break $\left(\varepsilon_{\mathrm{f}}\right)$ of PLA Tapioca $_{y}$ and PLA 90 Tapioca ${ }_{10}$ MDI are plotted in Figure 1. The $\sigma_{\mathrm{f}}$ of PLA is $48.3 \mathrm{MPa}$. After blending PLA with tapioca, PLA tapioca $_{y}$ specimens revealed a substantial reduction in $\sigma_{\mathrm{f}}$ and $\varepsilon_{\mathrm{f}}$. For example, the $\sigma_{\mathrm{f}}$ of PLA Tapioca $_{y}$ specimens was reduced from 48.3 to $17.5 \mathrm{MPa}$ as the tapioca content increased from 0 to $60 \mathrm{wt} \%$. When MDI was added, the $\sigma_{\mathrm{f}}$ of the PLA $x$ tapioca $y$ specimens was improved; the $\sigma_{\mathrm{f}}$ of PLA $_{40}$ Tapioca $_{60} \mathrm{MDI}$ was $42.6 \mathrm{MPa}$, whereas that of $\mathrm{PLA}_{40}$ Tapioca $_{60}$ was $25.1 \mathrm{MPa}$. This improvement in $\sigma_{\mathrm{f}}$ is due to the increase in the PLA Tapioca $_{y}$ interfacial adhesion, as a result of the formation of urethane linkages between MDI and PLA, as well as those between MDI and tapioca, because MDI acts as a coupling agent [21]. The $\varepsilon_{\mathrm{f}}$ for all samples are between $1 \%$ and $4 \%$; thus, their toughness is similar.

Figure 1. Tensile strength vs. tapioca content for ( $\mathbf{\Delta})$ PLA/tapioca and (घ) PLA/tapiocaMDI ${ }_{0.5}$; elongation at break vs. tapioca content for $(\Delta) \mathrm{PLA} /$ tapioca and (口) PLA/tapioca $\mathrm{MDI}_{0.5}$.

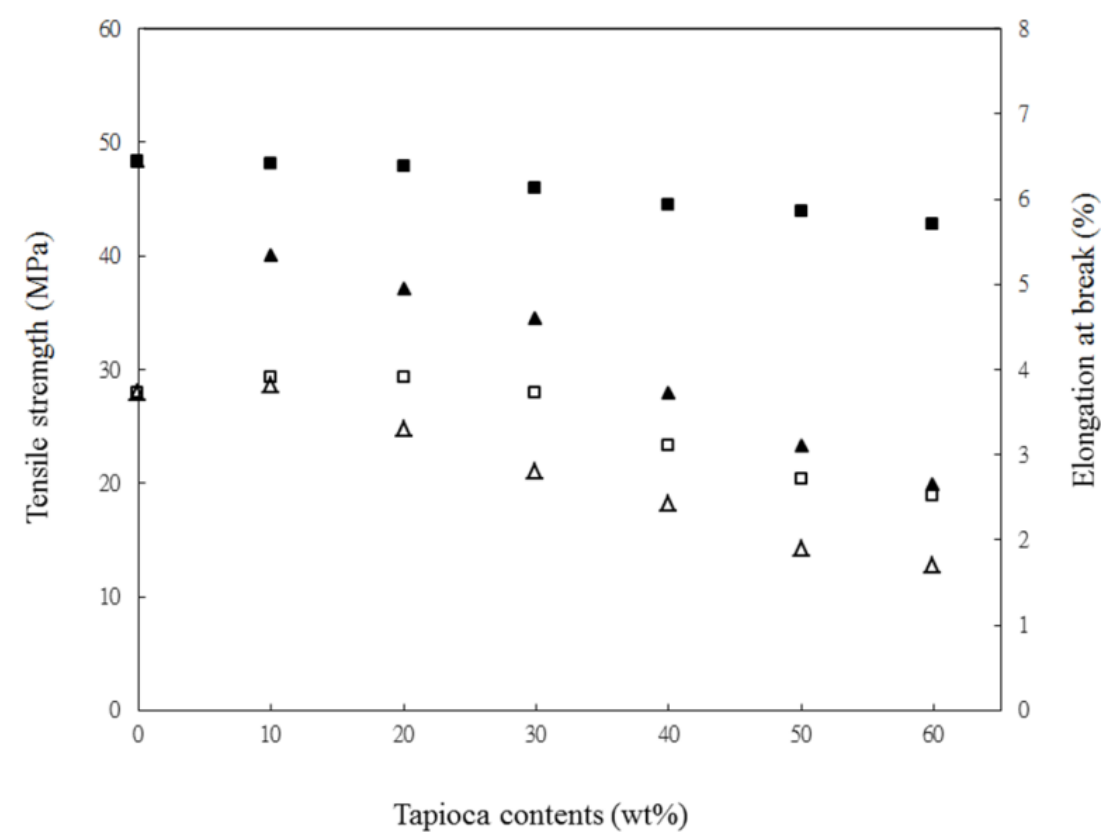

The $\sigma_{\mathrm{f}}$ and $\varepsilon_{\mathrm{f}}$ of PLA and PLA tapioca $_{y}$ MDI specimens as a function of ATBC are shown in Figures 2 and 3, respectively. With increasing plasticizer content, a common trend is shown by all series investigated: the $\sigma_{\mathrm{f}}$ decreases, whereas the $\varepsilon_{\mathrm{f}}$ increases. The $\sigma_{\mathrm{f}}$ of PLA $x$ tapioca $\mathrm{MDI}$ was reduced much more significantly after ATBC was added; the $\sigma_{\mathrm{f}}$ value of PLA $\mathrm{A}_{50}$ tapioca ${ }_{50} \mathrm{MDI}$ was reduced from 42.3 to $0.9 \mathrm{MPa}$, as the ATBC content was increased from 0 to $25 \mathrm{wt} \%$ (see Figure 2). This substantial reduction is due to the tapioca of PLA $_{x}$ tapioca $_{y} \mathrm{MDI}$ that could not be plasticized by ATBC. In

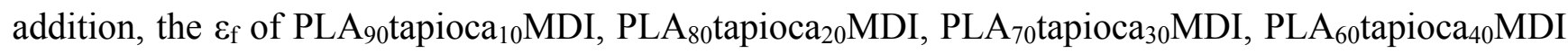


and PLA $_{50}$ tapioca ${ }_{50} \mathrm{MDI}$ approaches the maximum value at $357.3 \%, 289.7 \%, 178.8 \%, 102.5 \%$ and $56.3 \%$, respectively, as the ATBC content reaches an optimum value of 10 or $15 \mathrm{wt} \%$. The $\varepsilon_{\mathrm{f}}$ of the PLA $_{x}$ tapioca $y$ MDI specimens was reduced as the ATBC content increased from 10 or $15 \mathrm{wt} \%$. These results clearly suggest that the relatively poor ductility of PLA tapioca $_{y}$ MDI was improved after blending proper amounts of ATBC with the PLA Tapioca $_{y}$ MDI composites.

Figure 2. Tensile strength vs. ATBC content for (ם) PLA; (O) PLA (atapioca $_{10} \mathrm{MDI}_{0.5}$; (口) $\mathrm{PLA}_{80}$ tapioca ${ }_{20} \mathrm{MDI}_{0.5} ;(\diamond) \mathrm{PLA}_{70}$ tapioca ${ }_{30} \mathrm{MDI}_{0.5} ;(\Delta) \mathrm{PLA}_{60}$ tapioca ${ }_{40} \mathrm{MDI}_{0.5}$; and (×) PLA $_{50}$ tapioca ${ }_{50} \mathrm{MDI}_{0.5}$.

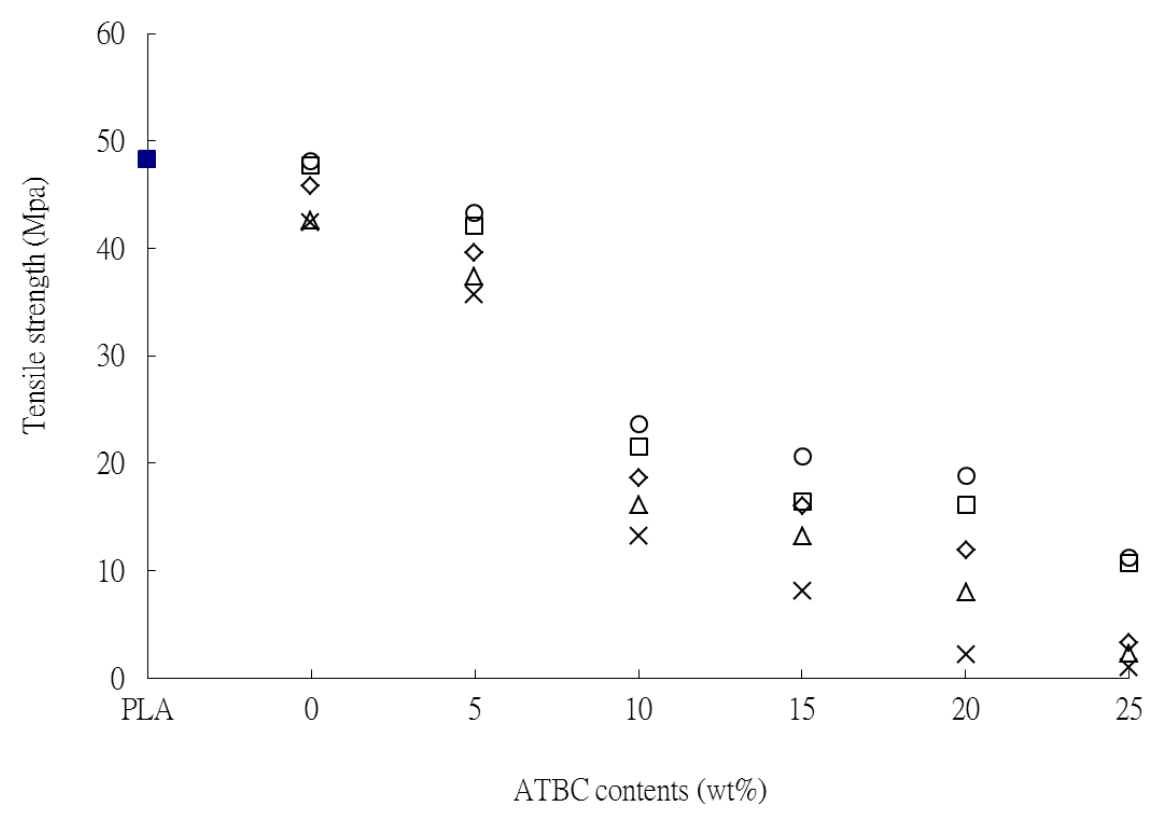

Figure 3. Elongation at break vs. ATBC content for (匹) PLA; ( $)$ PLA990tapioca ${ }_{10} \mathrm{MDI}_{0.5}$; (口) $\mathrm{PLA}_{80}$ tapioca ${ }_{20} \mathrm{MDI}_{0.5} ;(\diamond) \mathrm{PLA}_{70}$ tapioca ${ }_{30} \mathrm{MDI}_{0.5} ;(\Delta) \mathrm{PLA}_{60}$ tapioca ${ }_{40} \mathrm{MDI}_{0.5}$; and $(\times) \mathrm{PLA}_{50}$ tapioca ${ }_{50} \mathrm{MDI}_{0.5}$.

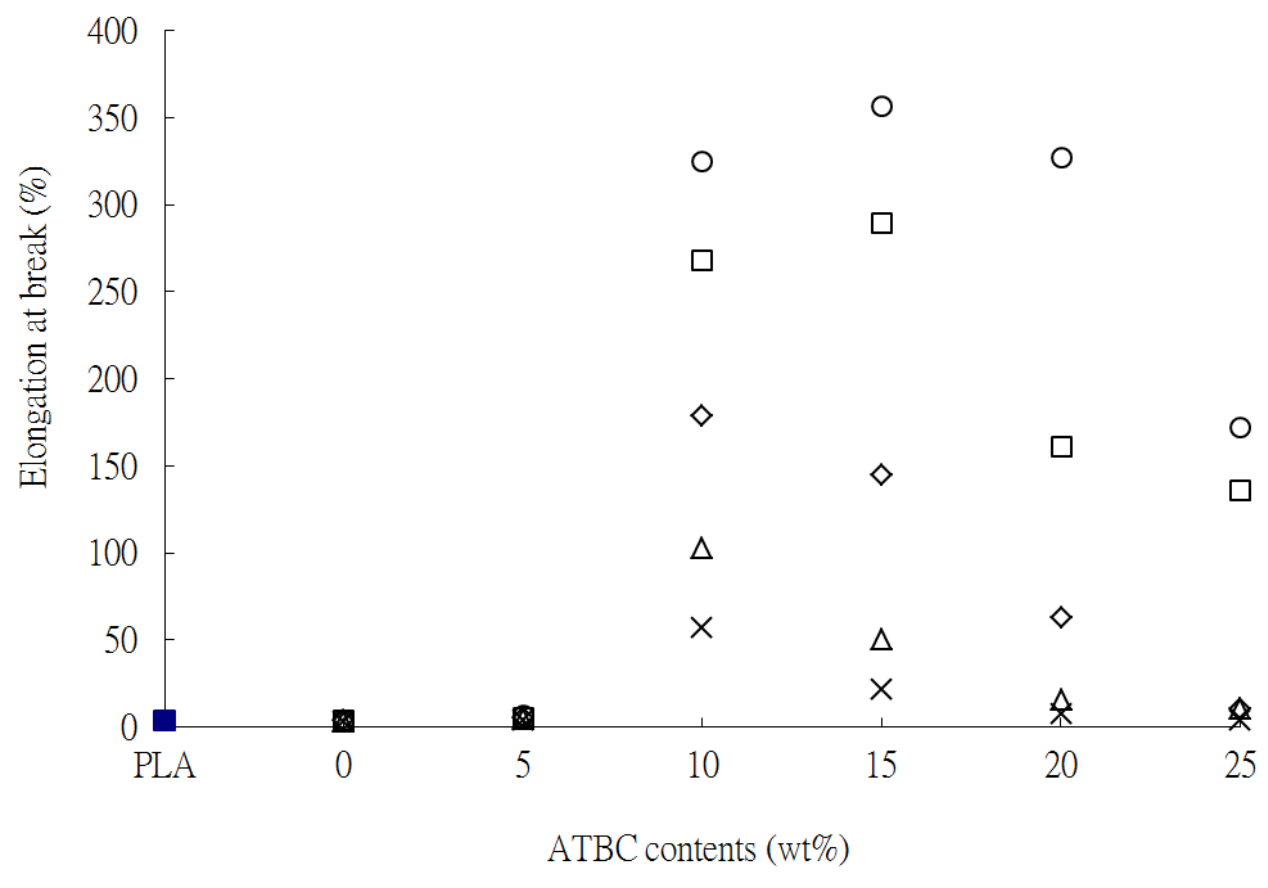




\subsection{Fourier Transform Infra-Red Spectroscopy}

Figure 4 illustrates typical FTIR spectra of PLA, tapioca, MDI, PLA tapioca $_{y}$ and PLA tapioca $_{y}$ MDI specimens. Four characteristic absorption bands centered at 1750, 2950, 2995 and $3510 \mathrm{~cm}^{-1}$, corresponding to the motions of $\mathrm{C}=\mathrm{O}$ bending, $\mathrm{C}-\mathrm{H}$ aliphatic stretching, $\mathrm{C}-\mathrm{H}$ aliphatic stretching (doublet) and $\mathrm{C}-\mathrm{O}-\mathrm{O}-\mathrm{H}$ stretching vibrations, respectively, were found in the spectrum of PLA

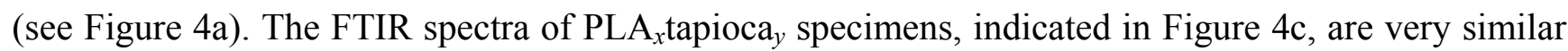
to those of PLA; the four main absorption bands centered at 1750, 2950, 2995 and $3510 \mathrm{~cm}^{-1}$ were also found in the spectra of PLA $x$ tapioca $y$ specimens. The absorption bands around 3000 to $3670 \mathrm{~cm}^{-1}$ were the O-H stretching vibration of tapioca. The FTIR spectra of PLA tapioca $_{y}$ specimens are very similar to those of PLA $_{x}$ tapioca $y$ MDI (see Figure 4d). However, the aforementioned 3000 to $3670 \mathrm{~cm}^{-1}$ absorption bands originally shown in the FTIR spectra of PLA were gradually replaced by a newly developed absorption band centered at $3315 \mathrm{~cm}^{-1}$, which corresponds to the motion of the amine $(\mathrm{N}-\mathrm{H})$ stretching vibration. The disappearance of the 3000 to $3670 \mathrm{~cm}^{-1}$ bending absorption bands and the appearance of 3315 and $1550 \mathrm{~cm}^{-1}(\mathrm{~N}-\mathrm{H})$ stretching absorption bands are attributed to the reaction of the hydroxyl $(\mathrm{O}-\mathrm{H})$ groups of tapioca molecules with the urethane $(\mathrm{N}=\mathrm{C}=\mathrm{O})$ groups of MDI and/or to the reaction of the carboxylic acid (C-O-O-H) groups of PLA molecules with the urethane groups of MDI during the melt-blending of PLA tapioca $_{y}$ specimens. The possible mechanism for PLA/tapioca/MDI composites is shown in Scheme 1.

Figure 4. FTIR of: (a) PLA; (b) tapioca; (c) PLA/tapioca; (d) PLA/tapioca/MDI; and (e) MDI.

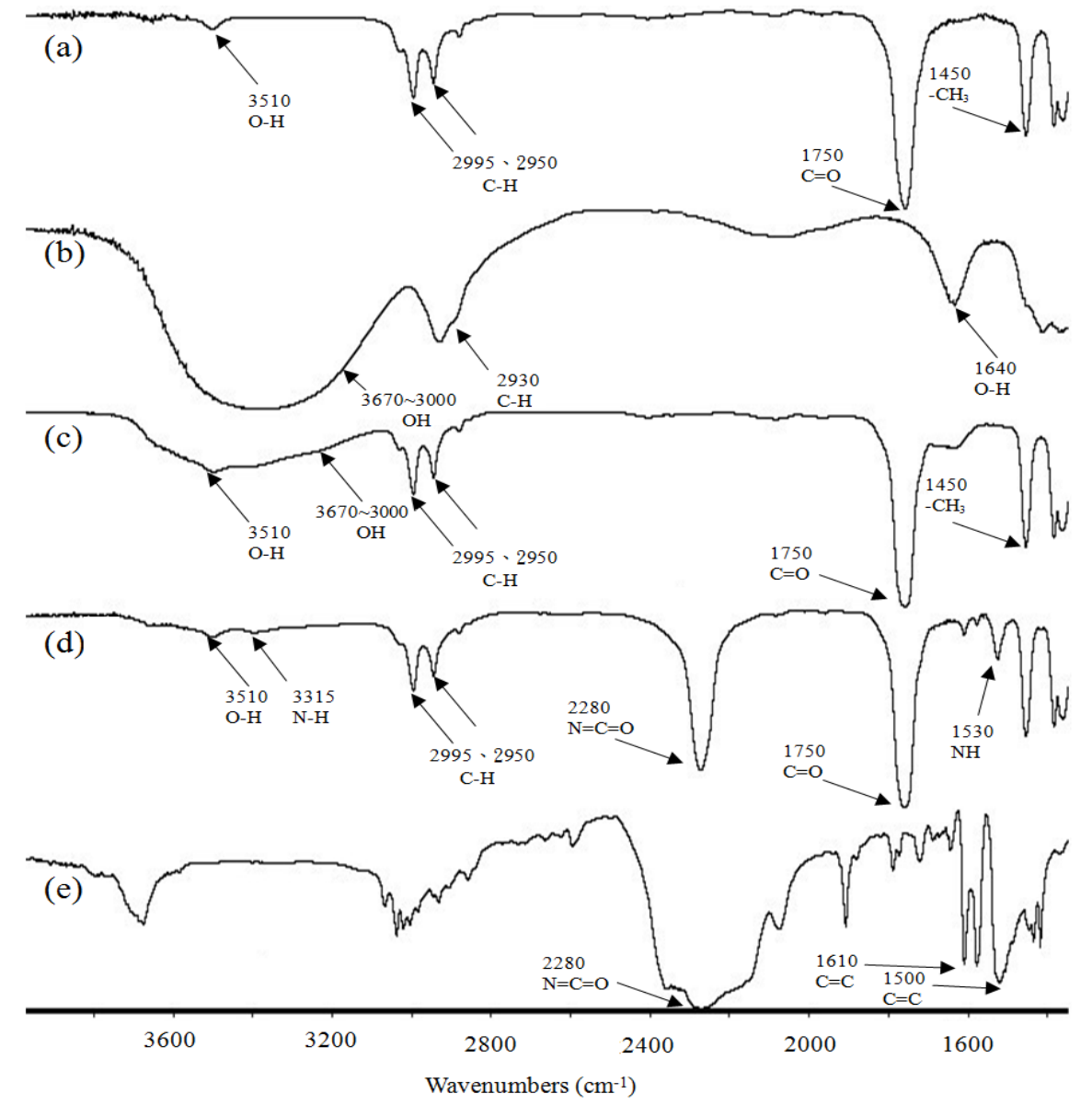


Scheme 1. Possible reactions for PLA/tapioca/MDI composites.

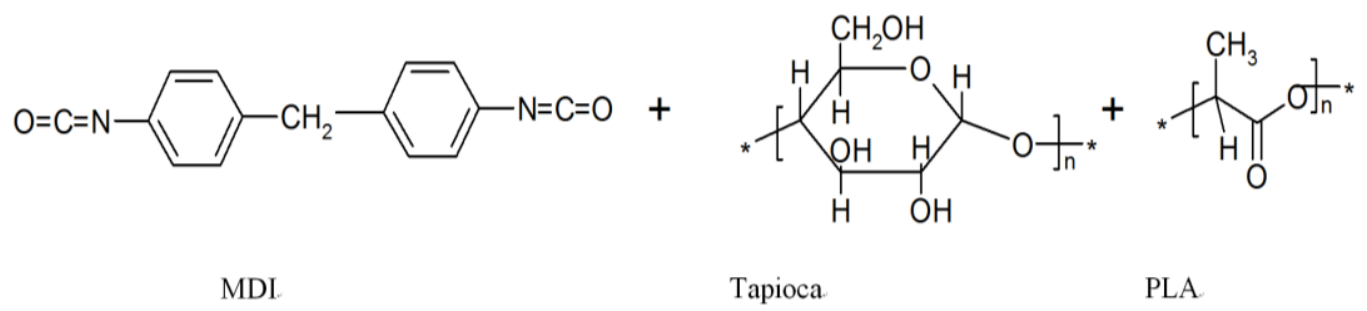

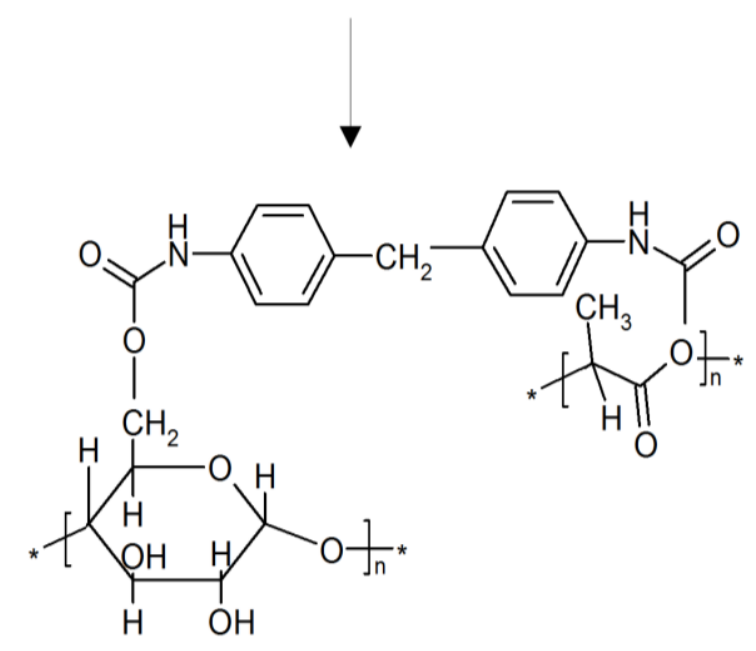

\subsection{Morphology Analysis}

Typical SEM micrographs of (PLA Ptapioca $\left._{30} \mathrm{MDI}\right)_{a} \mathrm{ATBC}_{b}$ specimens are shown in Figure 5. As shown in Figure 5a, a relatively brittle and smooth surface morphology was found for PLA. Tapioca is shown in Figure 5b. After blending PLA with tapioca, intervals between PLA and tapioca granules appeared (see Figure 5c) These results are similar to some reports on PLA/wheat starch [21] and PLA/corn starch blends [27,29]. This morphology is typical of incompatible blends, resulting in a poor tensile property, which is consistent with the result in Figure 1. After MDI was added, the compatibility of the PLA PLtapioca $_{30}$ specimen was improved (see Figure 5d). It shows excellent compatible morphologies, without the interval and voids associated with poor interfacial adhesion. The better compatibility of PLA to $_{70}$ tapca $_{30}$ MDI was due to the reaction of the hydroxyl groups of tapioca with the urethane groups of MDI and the reaction of the carboxylic acid groups of PLA with the urethane groups of MDI. The SEM micrographs of PLA Thapioca $_{30} \mathrm{MDI}$ as a function of the increasing ATBC content (from 5 to $25 \mathrm{wt} \%$ ) are shown in Figure $5 \mathrm{e}-\mathrm{h}$. The surface of PLA Th $^{\text {tapioca }}{ }_{30}$ MDI was still smooth and without intervals when the ATBC content was $5 \mathrm{wt} \%$. Furthermore, two phases can be seen after the ATBC content reaches $10 \mathrm{wt} \%$, which is the threshold limit value of high $\varepsilon_{\mathrm{f}}$ for $\left(\mathrm{PLA}_{70} \text { tapioca }_{30} \mathrm{MDI}\right)_{a} \mathrm{ATBC}_{b}$ specimens (see Figure 3). With increasing ATBC content, more demarcated plastic-deformed PLA debris or fibrils were found on the surface of PLA ${ }_{70}$ Tapioca $_{30} \mathrm{MDI}$ (see Figure $5 \mathrm{f}-\mathrm{i}$ ). This was attributed to the increasing distance between PLA molecules, or the exudation of ATBC, and also to the deterioration of the interfacial adhesion between tapioca and PLA. Therefore, the $\sigma_{\mathrm{f}}$ of $\mathrm{PLA}_{x}$ tapioca $\mathrm{MDI}$ decreased significantly with increasing ATBC. 
Figure 5. SEM for: (a) PLA; (b) tapioca; (c) $\mathrm{PLA}_{70}$ tapioca $_{30}$; (d) $\mathrm{PLA}_{70} \mathrm{Tapioca}_{30} \mathrm{MDI}_{0.5}$;

(e) $\quad\left(\mathrm{PLA}_{70} \text { tapioca }{ }_{30} \mathrm{MDI}_{0.5}\right)_{95} \mathrm{ATBC}_{5}$;

(f) $\quad\left(\mathrm{PLA}_{70} \text { tapioca }_{30} \mathrm{MDI}_{0.5}\right)_{90} \mathrm{ATBC}_{10}$;

(g) $\quad\left(\mathrm{PLA}_{70} \text { tapioca }_{30} \mathrm{MDI}_{0.5}\right)_{85} \mathrm{ATBC}_{15}$;

(h) $\left(\mathrm{PLA}_{70} \text { tapioca }_{30} \mathrm{MDI}_{0.5}\right)_{80} \mathrm{ATBC}_{20} ;$ and

(i) $\left(\mathrm{PLA}_{70} \text { tapioca }_{30} \mathrm{MDI}_{0.5}\right)_{75} \mathrm{ATBC}_{25}$.
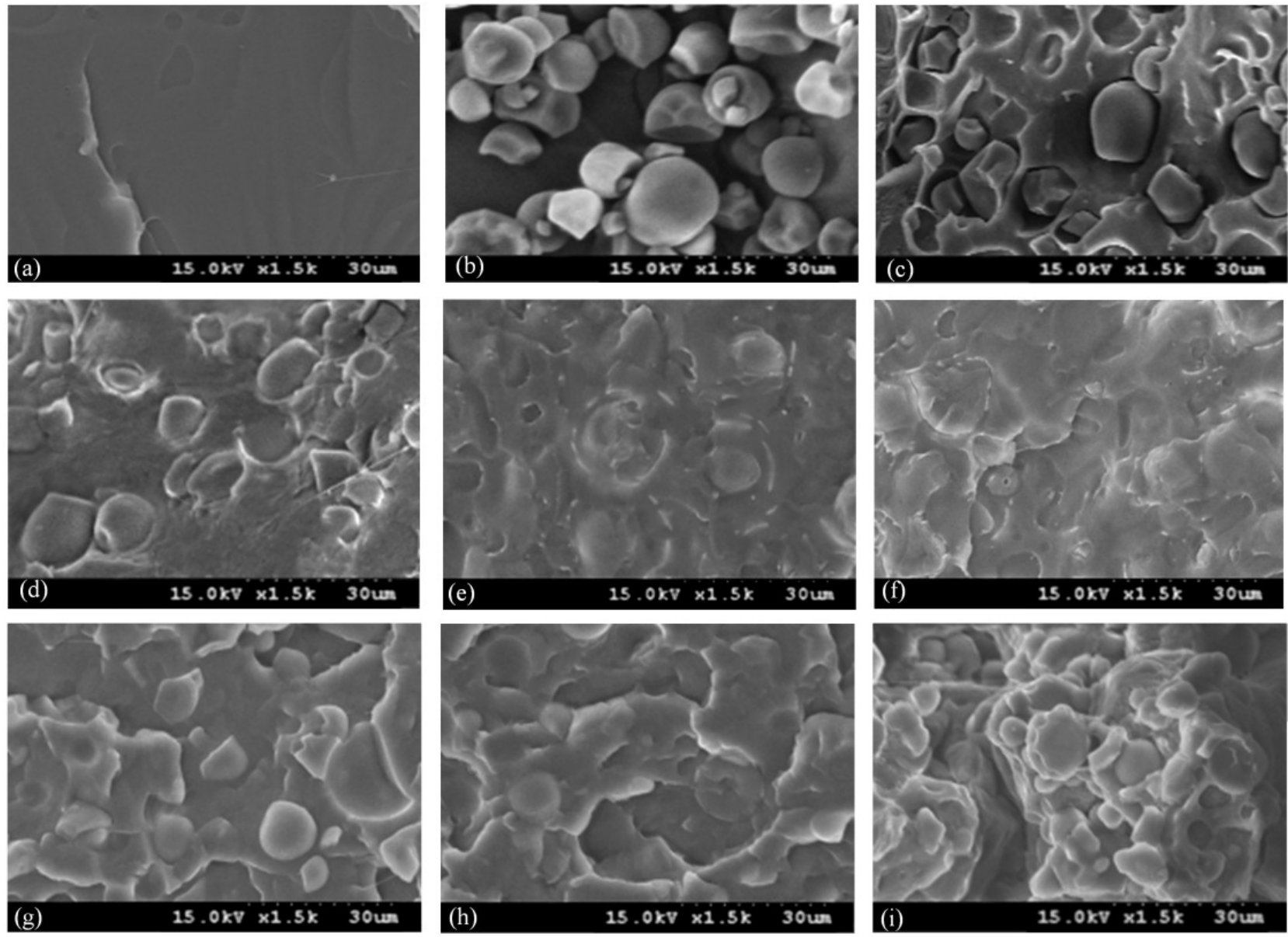

\subsection{Differential Scanning Calorimetry}

The thermal behavior of PLA and ( $\mathrm{PLA}_{70}$ tapioca $\left.{ }_{30} \mathrm{MDI}\right)_{a} \mathrm{ATBC}_{b}$ specimens was investigated. Figure 6 shows the DSC curves of PLA, the $\left(\mathrm{PLA}_{70} \text { tapioca }_{30} \mathrm{MDI}\right)_{a} \mathrm{ATBC}_{b}$ specimens and the plasticizer. The crystallization and melting enthalpies are identical, showing that PLA is totally amorphous after melt quenching. The DSC curves of PLA 70 tapioca ${ }_{30}$ MDI show a single glass transition that decreases with increasing ATBC concentration (from 0 to $25 \mathrm{wt} \%$ ). This result agrees with the data by Yeh et al. [50] and Baiardo et al. [51], who analyzed PLA/triacetin (TAc) and PLA/ATBC composites, respectively, over a more limited composition range (0\%-30\% TAc and ATBC). A decreasing $T_{\mathrm{g}}$ trend with increasing ATBC content is also shown in Figure 6, which is related to the cold crystallization and melting phenomena. 
Figure 6. DSC for: (a) PLA; (b) $\mathrm{PLA}_{70}$ tapioca $_{30} \mathrm{MDI}$; (c) $\left(\mathrm{PLA}_{70} \text { tapioca }_{30} \mathrm{MD}\right)_{95} \mathrm{ATBC}_{5}$; (d) $\left(\mathrm{PLA}_{70} \text { tapioca }_{30} \mathrm{MDI}\right)_{90} \mathrm{ATBC}_{10}$;

(e) $\left(\mathrm{PLA}_{70} \text { tapioca }_{30}\right)_{85} \mathrm{ATBC}_{15}$; (f) $\left(\mathrm{PLA}_{70} \text { tapioca }_{30} \mathrm{MDI}\right)_{a} \mathrm{ATBC}$; and (g) $\left(\mathrm{PLA}_{70} \text { tapioca }_{30} \mathrm{MDI}\right)_{75} \mathrm{ATBC}_{25}$.

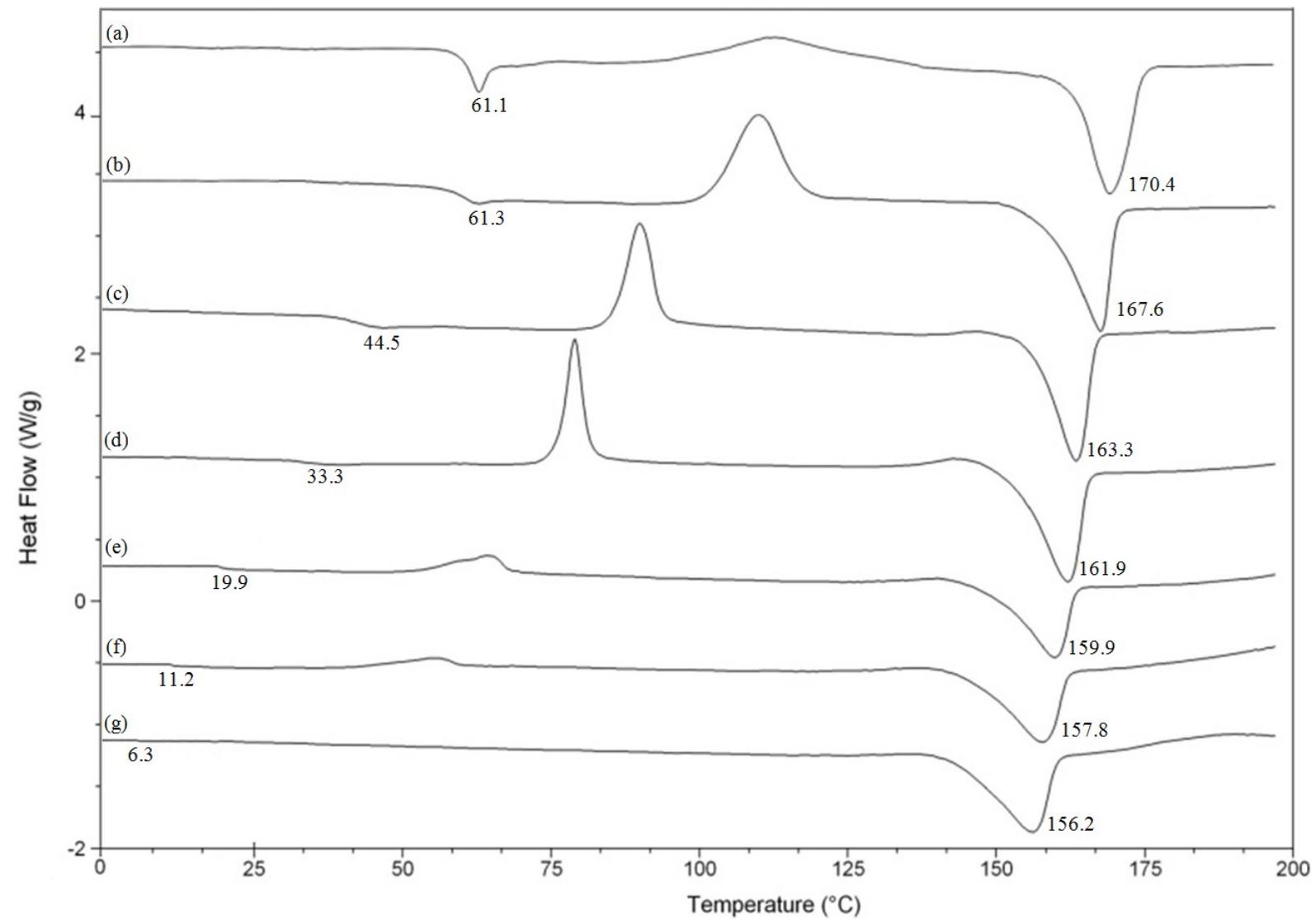

\subsection{Water Absorption}

Figure 7 presents data on the water absorption of the $\operatorname{PLA}_{x} \mathrm{ATBC}_{y}$ specimens as a function of varying tapioca content. It shows a rising water absorption rate with increasing tapioca content at the same ATBC content. Water absorption rates were $0.58 \%$ to $18.57 \%$ when the tapioca content was from $0 \%$ to $50 \%$ at $25 \%$ ATBC content. This is due to the hydrophilic property of tapioca, causing the percentage of water absorption to increase. Furthermore, water absorption rates increased when ATBC was added; the water absorption rate of $\mathrm{PLA}_{60}$ tapioca 40 was $4.91 \%$ to $11.85 \%$ when the ATBC content was from $0 \%$ to $25 \%$. ATBC is hydrophobic, but shows an interesting phenomenon of increasing moisture content. The trend of increasing water absorption is attributed to ATBC, which could enhance the free volume in PLA. This is evidenced by DSC analysis (see Figure 6): $T_{\mathrm{g}}$ decreased with increasing ATBC content. Therefore, the water molecule could be absorbed by PLA tapioca $_{y}$ easily when the ATBC content increased the mobility of PLA molecules. The water adsorption for the lower tapioca content (10\% to $30 \%$ ) was first increasing and then decreasing. This might be due to slight exudation when the ATBC content is from $10 \%$ to $25 \%$. It could be evidenced from the morphology analysis. The phase separation may be because of the exudation of ATBC; the phase separation worsens when the amount of ATBC was higher than 10\% (See Figure 5f-i). However, when the tapioca content approached $40 \%$ and $50 \%$, the ATBC might be absorbed by tapioca. Therefore, the exudation effect might not be apparent. On the basis of the results from the tensile property, 
morphology analysis and water absorption, the miscibility limits of ATBC content are suggested to be $10 \%$ for $\mathrm{PLA}_{x}$ tapioca $_{y} \mathrm{MDI}_{0.5}$ composites.

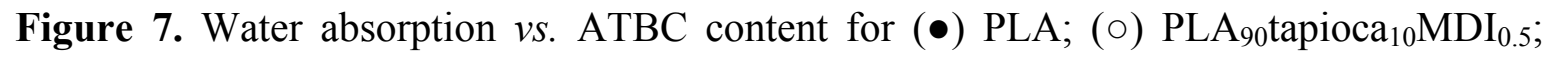
(口) $\mathrm{PLA}_{80}$ tapioca ${ }_{20} \mathrm{MDI}_{0.5} ;(\diamond) \mathrm{PLA}_{70}$ tapioca ${ }_{30} \mathrm{MDI}_{0.5} ;(\Delta) \mathrm{PLA}_{60}$ tapioca ${ }_{40} \mathrm{MDI}_{0.5}$; and (×) $\mathrm{PLA}_{50}$ tapioca $_{50} \mathrm{MDI}_{0.5}$.

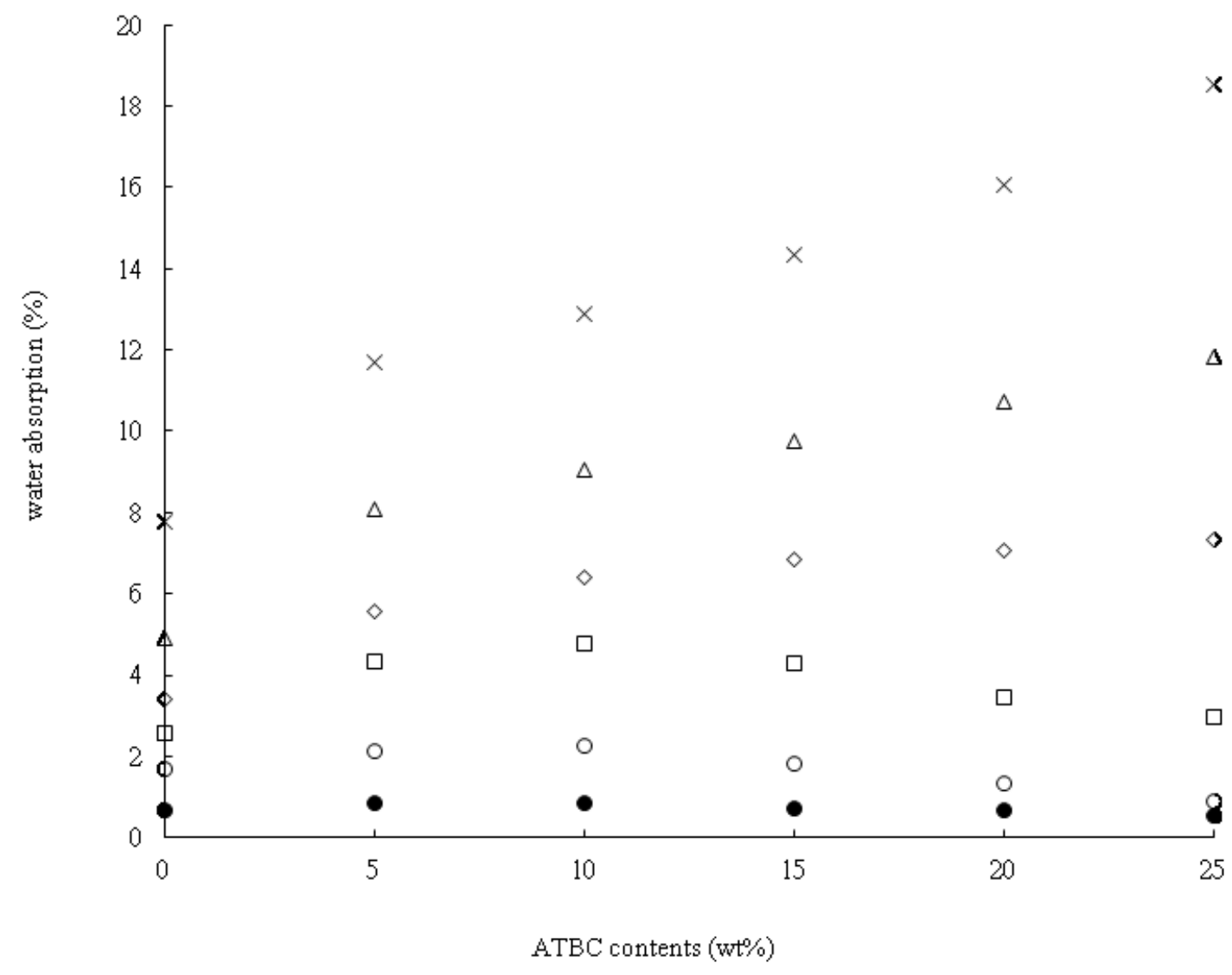

\subsection{Enzymatic Hydrolysis}

The weight loss of $\mathrm{PLA}_{70}$ tapioca $_{30} \mathrm{MDI}$ and (PLA (tapioca $\left._{30} \mathrm{MDI}\right)_{a} \mathrm{ATBC}_{b}$ at varying enzymatic hydrolysis time is indicated in Figure 8. It shows a common result: the increasing percentage of weight loss for all series, as the hydrolysis time increases. The weight loss of PLA totapioca $_{30}$ MDI increased significantly from $0.33 \%$ to $11.82 \%$, as the ATBC content increased from 0 to $25 \mathrm{wt} \%$ after $120 \mathrm{~h}$ of hydrolysis time. Enzymes could attack the molecules of PLA easily after ATBC was blended with PLA $_{70}$ tapioca $_{30}$ MDI. Furthermore, the interfacial adhesion between PLA and tapioca might deteriorate when ATBC was added. The weight loss increased significantly when the ATBC content was higher than $5 \%$. The migration of ATBC occurred from $10 \%$ content. This conjecture of exudation was evidenced by the morphological analysis and water absorption. 


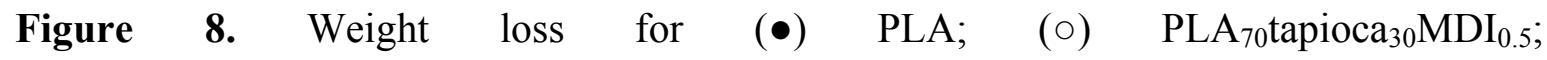
$(\square) \quad\left(\mathrm{PLA}_{70} \text { tapioca }_{30} \mathrm{MDI}_{0.5}\right)_{95} \mathrm{ATBC}_{5} ; \quad(\diamond) \quad\left(\mathrm{PLA}_{70} \text { tapioca }{ }_{30} \mathrm{MDI}_{0.5}\right)_{90} \mathrm{ATBC}_{10}$; $(\Delta) \quad\left(\mathrm{PLA}_{70} \text { tapioca }_{30} \mathrm{MDI}_{0.5}\right)_{85} \mathrm{ATBC}_{15} ; \quad(\times) \quad\left(\mathrm{PLA}_{70} \text { tapioca }_{30} \mathrm{MDI}_{0.5}\right)_{80} \mathrm{ATBC}_{20} ; \quad$ and $(+)\left(\mathrm{PLA}_{70} \text { tapioca }_{30} \mathrm{MDI}_{0.5}\right)_{75} \mathrm{ATBC}_{25}$.

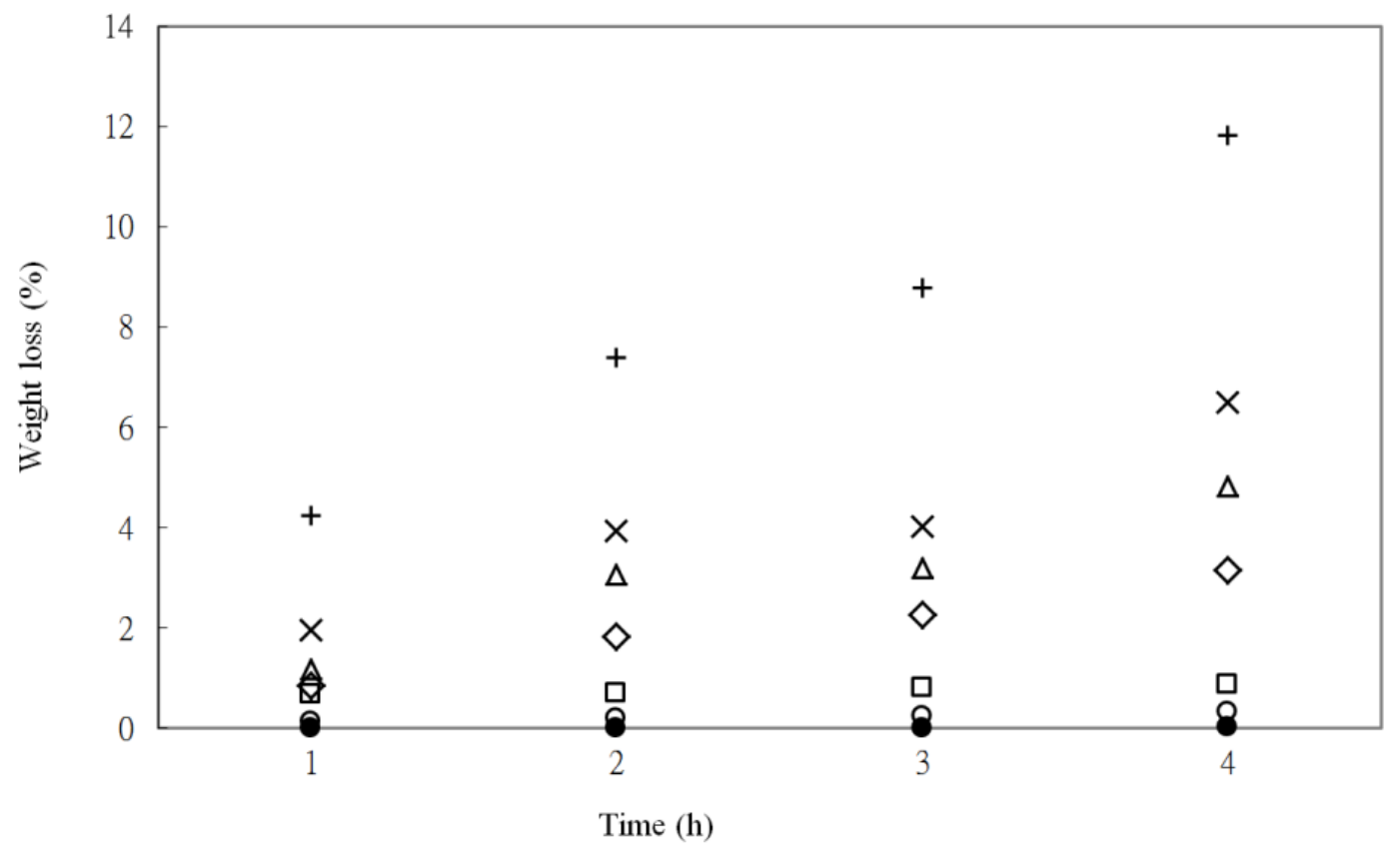

\section{Experimental Section}

\subsection{Materials and Preparation}

PLA resin, with a trade name of Nature Green 4032D, was obtained from Cargill-Dow. Tapioca was purchased from United Global Agencies (Bangkok, Thailand). Before melt-blending, PLA and tapioca were dried in a vacuum oven at $80{ }^{\circ} \mathrm{C}$ for $8 \mathrm{~h}$ to remove the residual water. Acetyl tributyl citrate (ATBC-food grade) was supplied by Chou Feng Enterprise Co., Ltd. (Shulin, Taiwan). Dried components of PLA/starch at varying weight ratios were melt-blended using a Brabender. Three compounds were evaluated: PLA $x$ Tapioca $y$, PLA $_{x}$ Tapioca $_{y} \mathrm{MDI}$ and $\left(\mathrm{PLA}_{x} \text { Tapioca }_{y} \mathrm{MDI}\right)_{a} \mathrm{ATBC}{ }_{b}$. During each compounding process, the Brabender was operated at a temperature of $190{ }^{\circ} \mathrm{C}$ and a screw speed of $120 \mathrm{rpm}$ for $3 \mathrm{~min}$ for all samples without ATBC and for an additional 2 min after adding ATBC. All prepared series were then hot-pressed at $190{ }^{\circ} \mathrm{C}$ and $10 \mathrm{MPa}$ for 2 min and then cooled in air at about $25{ }^{\circ} \mathrm{C}$. The compositions of all specimens are summarized in Table 1. Before hot-pressing, the specimens were dried in a vacuum oven at $80^{\circ} \mathrm{C}$ for $12 \mathrm{~h}$.

Table 1. Compositions of PLA, PLA tapioca $_{y}$, PLA $x$ tapioca MDI $_{y}$ and $\left(\mathrm{PLA}_{x} \text { tapioca }_{y} \mathrm{MDI}\right)_{a} \mathrm{ATBC}_{b}$ specimens.

\begin{tabular}{ccccc}
\hline Sample & PLA (\%) & Tapioca (\%) & ATBC (\%) & MDI (phr) \\
\hline PLA & 100 & 0 & 0 & 0 \\
PLA $_{90}$ tapioca $_{10}$ & 90 & 10 & 0 & 0 \\
PLA $_{80}$ tapioca $_{20}$ & 80 & 20 & 0 & 0 \\
PLA $_{70}$ tapioca $_{30}$ & 70 & 30 & 0 & 0 \\
\hline
\end{tabular}


Table 1. Cont.

\begin{tabular}{|c|c|c|c|c|}
\hline Sample & PLA (\%) & Tapioca (\%) & АТBC (\%) & MDI (phr) \\
\hline PLA $_{60}$ tapioca $_{40}$ & 60 & 40 & 0 & 0 \\
\hline PLA $_{50}$ tapioca $_{50}$ & 50 & 50 & 0 & 0 \\
\hline PLA $_{40}$ tapioca $_{60}$ & 0 & 60 & 0 & 0 \\
\hline PLA $_{90}$ tapioca $_{10}$ MDI & 90 & 10 & 0 & 0.5 \\
\hline PLA $_{80}$ tapioca $_{20}$ MDI & 80 & 20 & 0 & 0.5 \\
\hline PLA $_{70}$ tapioca $_{30}$ MDI & 70 & 30 & 0 & 0.5 \\
\hline PLA $_{60}$ tapioca $_{40}$ MDI & 60 & 40 & 0 & 0.5 \\
\hline PLA $_{50}$ tapioca $_{50}$ MDI & 50 & 50 & 0 & 0.5 \\
\hline PLA $_{60}$ tapioca $_{40}$ MDI & 40 & 60 & 0 & 0.5 \\
\hline$\left(\mathrm{PLA}_{90} \text { tapioca }_{10} \mathrm{MDI}\right)_{95} \mathrm{ATBC}_{5}$ & 85.5 & 9.5 & 5 & 0.5 \\
\hline$\left(\mathrm{PLA}_{80} \text { tapioca }_{20} \mathrm{MDI}\right)_{95} \mathrm{ATBC}_{5}$ & 76 & 19 & 5 & 0.5 \\
\hline$\left(\mathrm{PLA}_{70} \text { tapioca }_{30} \mathrm{MDI}\right)_{95} \mathrm{ATBC}_{5}$ & 66.5 & 28.5 & 5 & 0.5 \\
\hline$\left(\mathrm{PLA}_{60} \text { tapioca }_{40} \mathrm{MDI}\right)_{95} \mathrm{ATBC}_{5}$ & 57 & 38 & 5 & 0.5 \\
\hline$\left(\mathrm{PLA}_{50} \text { tapioca }_{50} \mathrm{MDI}\right)_{95} \mathrm{ATBC}_{5}$ & 47.5 & 47.5 & 5 & 0.5 \\
\hline$\left(\mathrm{PLA}_{90} \text { tapioca }_{10} \mathrm{MDI}\right)_{90} \mathrm{ATBC}_{10}$ & 81 & 9 & 10 & 0.5 \\
\hline$\left(\mathrm{PLA}_{80} \mathrm{tapioca}_{20} \mathrm{MDI}\right)_{90} \mathrm{ATBC}_{10}$ & 72 & 18 & 10 & 0.5 \\
\hline$\left(\mathrm{PLA}_{70} \mathrm{tapioca}_{30} \mathrm{MDI}\right)_{90} \mathrm{ATBC}_{10}$ & 63 & 27 & 10 & 0.5 \\
\hline$\left(\mathrm{PLA}_{60} \mathrm{tapioca}_{40} \mathrm{MDI}\right)_{90} \mathrm{ATBC}_{10}$ & 54 & 36 & 10 & 0.5 \\
\hline$\left(\mathrm{PLA}_{50} \mathrm{tapioca}_{50} \mathrm{MDI}\right)_{90} \mathrm{ATBC}_{10}$ & 45 & 45 & 10 & 0.5 \\
\hline$\left(\mathrm{PLA}_{90} \text { tapioca }_{10} \mathrm{MDI}\right)_{85} \mathrm{ATBC}_{15}$ & 76.5 & 8.5 & 15 & 0.5 \\
\hline$\left(\mathrm{PLA}_{80} \mathrm{tapioca}_{20} \mathrm{MDI}\right)_{85} \mathrm{ATBC}_{15}$ & 68 & 17 & 15 & 0.5 \\
\hline$\left(\mathrm{PLA}_{70} \mathrm{tapioca}_{30} \mathrm{MDI}\right)_{85} \mathrm{ATBC}_{15}$ & 59.5 & 25.5 & 15 & 0.5 \\
\hline$\left(\mathrm{PLA}_{60} \mathrm{tapioca}_{40} \mathrm{MDI}\right)_{85} \mathrm{ATBC}_{15}$ & 51 & 34 & 15 & 0.5 \\
\hline$\left(\mathrm{PLA}_{50} \mathrm{tapioca}_{50} \mathrm{MDI}\right)_{85} \mathrm{ATBC}_{15}$ & 42.5 & 42.5 & 15 & 0.5 \\
\hline$\left(\mathrm{PLA}_{90} \text { tapioca }_{10} \mathrm{MDI}\right)_{80} \mathrm{ATBC}_{20}$ & 72 & 8 & 20 & 0.5 \\
\hline$\left(\mathrm{PLA}_{80} \mathrm{tapioca}_{20} \mathrm{MDI}\right)_{80} \mathrm{ATBC}_{20}$ & 64 & 16 & 20 & 0.5 \\
\hline$\left(\mathrm{PLA}_{70} \mathrm{tapioca}_{30} \mathrm{MDI}\right)_{80} \mathrm{ATBC}_{20}$ & 56 & 24 & 20 & 0.5 \\
\hline$\left(\mathrm{PLA}_{60} \mathrm{tapioca}_{40} \mathrm{MDI}\right)_{80} \mathrm{ATBC}_{20}$ & 48 & 32 & 20 & 0.5 \\
\hline$\left(\mathrm{PLA}_{50} \mathrm{tapioca}_{50} \mathrm{MDI}\right)_{80} \mathrm{ATBC}_{20}$ & 40 & 40 & 20 & 0.5 \\
\hline$\left(\mathrm{PLA}_{90} \text { tapioca }_{10} \mathrm{MDI}\right)_{75} \mathrm{ATBC}_{25}$ & 67.5 & 7.5 & 25 & 0.5 \\
\hline$\left(\mathrm{PLA}_{80} \mathrm{tapioca}_{20} \mathrm{MDI}\right)_{75} \mathrm{ATBC}_{25}$ & 60 & 15 & 25 & 0.5 \\
\hline$\left(\mathrm{PLA}_{70} \text { tapioca }_{30} \mathrm{MDI}\right)_{75} \mathrm{ATBC}_{25}$ & 52.2 & 22.5 & 25 & 0.5 \\
\hline$\left(\mathrm{PLA}_{60} \text { tapioca }_{40} \mathrm{MDI}\right)_{75} \mathrm{ATBC}_{25}$ & 45 & 30 & 25 & 0.5 \\
\hline$\left(\mathrm{PLA}_{50} \mathrm{tapioca}_{50} \mathrm{MDI}\right)_{75} \mathrm{ATBC}_{25}$ & 37.5 & 37.5 & 25 & 0.5 \\
\hline
\end{tabular}

\subsection{Tensile Property}

The tensile properties of the hot-pressed PLA, PLA Tapioca $_{y}$ and $\left(\mathrm{PLA}_{x}\right.$ Tapioca $\left._{y}\right) /$ ATBC specimens at $25{ }^{\circ} \mathrm{C}$ were determined using a tensile testing machine (model AG-10KNA, Shimadzu Corporation, Kyoto, Japan) with a crosshead speed of $50 \mathrm{~mm} / \mathrm{min}$. A $35-\mathrm{mm}$ gauge length was used for each tensile experiment. Dog-bone-shaped specimens were prepared according to the ASTM D638 Type IV standard [52]. On the basis of the average tensile results of at least five tensile specimens, the values of tensile strength and elongation at break were obtained. 


\subsection{Fourier Transform Infra-Red Spectroscopy}

FTIR measurements were performed on a PerkinElmer spectrometer (model Spectrum One, PerkinElmer Inc., Waltham, MA, USA). The spectra of the samples were obtained by averaging 15 scans, with a wavenumber range of 4000 to $650 \mathrm{~cm}^{-1}$ and a resolution of $2 \mathrm{~cm}^{-1}$.

\subsection{Morphology Analysis}

The morphology of specimens, before and after the hydrolytic degradation, was observed by using a scanning electron microscope (model SU1510, Hitachi High-Technologies Corporation, Tokyo, Japan). Specimens of a $2 \times 2 \mathrm{~cm}^{2}$ area were fixed on a sample holder using a conductive adhesive tape. They were coated with a thin layer of gold at $15 \mathrm{keV}$ for $15 \mathrm{~s}$ to improve the image resolution and were then photographed at $3.00 \mathrm{~K}$ magnification and a low voltage of $2.1 \mathrm{kV}$.

\subsection{Differential Scanning Calorimetry}

The thermal properties of PLA composite resins were determined using a TA Q100 differential scanning calorimetry (DSC). All DSC scans were performed at a heating rate of $10{ }^{\circ} \mathrm{C} / \mathrm{min}$ and under flowing nitrogen with a flow rate of $50 \mathrm{~mL} / \mathrm{min}$. The DSC was calibrated using pure indium. For $T_{\mathrm{g}}$ and $T_{\mathrm{m}}$ determination, samples weighing approximately $0.5 \mathrm{mg}$ were placed in standard aluminum-sample pans.

\subsection{Water Absorption}

Five specimens $(10 \mathrm{~mm} \times 10 \mathrm{~mm} \times 0.5 \mathrm{~mm})$ were used for the water absorption test. After conditioning in desiccators for three weeks, specimens were weighed. They were immersed in distilled water at room temperature for $24 \mathrm{~h}$. Then, they were dabbed with tissue paper to remove the water from the surface. Water absorption was calculated using the following Equation (1):

$$
\mathrm{WA}(\%)=\frac{W_{1-} W_{0}}{W_{0}} \times 100
$$

where $W_{0}$ is the weight of the dry sample and $W_{1}$ is the weight of the sample immersed in distilled water for $24 \mathrm{~h}$.

\subsection{Enzymatic Hydrolysis}

The degradation of the enzymatic hydrolysis of specimens was evaluated at $27{ }^{\circ} \mathrm{C}$ using $50 \mathrm{mg}$ starch enzyme in $\left(0.025 \mathrm{~mol} \mathrm{Na}_{2} \mathrm{HPO}_{4}+0.025 \mathrm{~mol} \mathrm{KH}_{2} \mathrm{PO}_{4}\right)$ aqueous solution. Specimens with a dimension of $5 \times 5 \mathrm{~cm}^{2}$ were tested for various days, washed with distilled water and dried completely in a vacuum oven at $70{ }^{\circ} \mathrm{C}$ for $8 \mathrm{~h}$. On the basis of weight loss, the degree of degradation was determined using Equation (2):

$$
\text { weight loss }=\frac{W_{1-} W_{0}}{W_{0}} \times 100 \%
$$

where $W_{0}$ is the dry weight before degradation and $W_{\mathrm{t}}$ is the dry weight at time $t$. 


\section{Conclusions}

The $\sigma_{\mathrm{f}}$ of PLA $_{x}$ tapioca $_{y}$ MDI specimens was significantly higher than that of PLA tapioca $_{y}$ specimens. The $\varepsilon_{\mathrm{f}}$ of PLA and PLA $x$ tapioca $y$ MDI specimens approached the maximum value, as the ATBC content reached an optimum value of 10 and $15 \mathrm{wt} \%$, respectively. The threshold limits of the $\varepsilon_{\mathrm{f}}$ were high when the ATBC content was $10 \mathrm{wt} \%$. FTIR demonstrated the disappearance of the 3000 to $3670 \mathrm{~cm}^{-1}$ bending absorption band and the appearance of the 3315 and $1550 \mathrm{~cm}^{-1} \mathrm{NH}$ stretching absorption band, which were attributed to the reaction of the $\mathrm{OH}$ groups of tapioca molecules with the $\mathrm{N}=\mathrm{C}=\mathrm{O}$ groups of MDI and/or to the reaction of the $\mathrm{C}-\mathrm{O}-\mathrm{O}-\mathrm{H}$ groups of PLA molecules with the urethane groups of MDI during the melt-blending of PLA $x$ tapioca $y$ specimens. SEM micrographs revealed the intervals between PLA and tapioca. Voids from the matrix of PLA tapioca $_{y}$ were significantly improved after MDI was added. Furthermore, two phases can be seen after the ATBC content reached $10 \mathrm{wt} \%$. This is due to the exudation of ATBC; with increasing ATBC content, more demarcated plastic deformation was found on the surface of PLA $\mathrm{A}_{70}$ Tapioca $_{30}$ MDI. DSC curves of the PLA $_{70}$ tapioca $_{30}$ MDI specimen showed a single glass transition and cold crystallization that decreased as the ATBC content increased from 0 to $25 \mathrm{wt} \%$. The increasing trend of water absorption with increasing ATBC content was attributed to the increasing free volume in PLA, causing the water molecules to be easily absorbed in the PLA $x$ tapioca $y$ specimens. Enzymatic hydrolysis tests indicated that the weight loss of PLA 70 $_{0}$ tapioca $_{30}$ MDI increased significantly as the ATBC content increased.

\section{Acknowledgments}

The authors express their appreciation to Grabio Greentech Corporation, Ching-Yung Trading Co., Ltd., Fabric King Textile Co., Ltd., Ministry of Economic Affairs (100-EC-17-A-10-S1-186) and the National Science Council (NSC 102-2221-E-161-011, NSC 100-3113-E-033-001 and NSC 102-2221-E-003-065) for support of this work.

\section{Author Contributions}

All authors contributed to this study. Chi-Hui Tsou and Wei-Song Hung designed the research and wrote this paper. Chi-Hui Tsou, Maw-Cherng Suen, and Chih-Yuan Tsou edited the paper and gave final approval of the version to be submitted. Chih-Yuan Tsou and Ruo Yao Wang did the analysis. Manuel De Guzman, Chien-Chieh Hu, and Kueir-Rarn Lee also contributed in analyzing data and in rewriting the revised manuscript. Jen-Taut Yeh, Wei-Hua Yao, Chin-San Wu, Shih-Hsuan Chiu, Jui-Chin Chen, Shang-Ming Lin, and Manuel De Guzman supervised the conduct of experiments and performed the theoretical analysis of the data.

\section{Conflicts of Interest}

The authors declare no conflict of interest.

\section{References}

1. Handra, R.; Rustgi, R. Biodegradable polymers. Prog. Polym. Sci. 1998, 23, 1273-1335. 
2. Warwel, S.; Brüse, F.; Demes, C.; Kunz, M.; Rüsch gen Klaas, M. Polymers and surfactants on the basis of renewable resources. Chemosphere 2001, 43, 39-48.

3. Tsutsumi, N.; Kono, Y.; Oya, M.; Sakai, W.; Nagata, M. Recent development of biodegradable network polyesters obtained from renewable natureal resources. Clean Soil Air Water 2008, 36, 682-686.

4. Sinclair, R.G.J. The case for polylactic acid as a commodity packaging plastic. Macromol. Sci. Pure Appl. Chem. 1996, 33, 585-597.

5. Kricheldorf, H.R.; Kreiser-Saunders, I. Polylactides-Synthesis, characterization and medical application. Macromol. Symp. 1996, 103, 85-102.

6. Jang, W.Y.; Shin, B.Y.; Lee, T.J.; Narayan, R. Thermal properties and morphology of biodegradable PLA/starch compatibilized blends. J. Ind. Eng. Chem. 2007, 1, 457-464.

7. Oksman, K.; Skrifvars, M.; Selin, J.F. Natural fibres as reinforcement in polylactic acid (PLA) composites. Compos. Sci. 2003, 63, 1317-1324.

8. Shanks, R.A.; Hodzic, A.; Ridderhof, D. Composites of poly(lactic acid) with flax fibers modified by interstitial polymerization. J. Appl. Polym. Sci. 2006, 101, 3620-3629.

9. Bodros, E.; Pillin, I.; Montrelay, N.; Baley, C. Could biopolymers reinforced by randomly scattered flax fiber be used in structural applications. Compos. Sci. Technol. 2007, 67, 462-470.

10. Alvarez, V.A.; Ruscekaite, R.A.; Vázquez, A. Mechanical properties and water absorption behavior of composites made from a biodegradable matrix and alkaline-treated sisal fibers. J. Compos. Mater. 2003, 37, 1575-1588.

11. Lee, S.Y.; Kang, I.A.; Doh, G.H.; Yoon, H.G.; Park, B.D.; Wu, Q. Thermal and mechanical properties of wood flour/talc-filled polylactic acid composites: Effect of filler content and coupling treatment. J. Thermoplast. Compos. Mater. 2008, 21, 209-223.

12. Shibata, M.; Ozawa, K.; Teramoto, N.; Yosomiya, R.; Takeishi, H. Biocomposites made from short abaca fiber and biodegradable polyesters. Macromol. Mater. Eng. 2003, 288, 35-43.

13. Plackett, D.; Andersen, T.L.; Pedersen, W.B.; Nielsen, L. Biodegradable composites based on L-polylactide and jute fibres. Compos. Sci. Technol. 2003, 63, 1287-1296.

14. Shibata, M.; Oyamada, S.; Kobayashi, S.I.; Yaginuma, D. Mechanical properties and biodegradability of green composites based on biodegradable polyesters and lyocell fabric. J. Appl. Polym. Sci. 2004, 92, 3857-3863.

15. Huda, M.S.; Drzal, L.T.; Misra, M.; Mohanty, A.K. Wood-fiber-reinforced poly(lactic acid) composites: Evaluation of the physicomechanical and morphological properties. J. Appl. Polym. Sci. 2006, 102, 4856-4869.

16. Huda, M.S.; Drzal, L.T.; Misra, M.; Mohanty, A.K.; Williams, K.; Mielewski, D.F. A study onbiocomposites from recycled newspaper fiber and poly(lactic acid). Ind. Eng. Chem. Res. 2005, 44, 5593-5601.

17. Liu, W.; Misra, M.; Askeland, P.; Drzal, L.; Mohanty, A.K. Green composites from soy based plastic and pineapple leaf fiber: Fabrication and properties evaluation. Polymer 2005, 46, 2710-2721.

18. Ardente, F.; Beccali, M.; Cellura, M.; Mistretta, M. Building energy performance: A LCA case study of kenaf-fibres insulation board. Energy Build. 2008, 40, 1-10.

19. Mathew, A.P.; Oksman, K.; Sain, M. Mechanical properties of biodegradable composites from poly lactic acid (PLA) and microcrystalline cellulose (MCC). J. Appl. Polym. Sci. 2005, 97, 10-20. 
20. Avella, M.; Buzarovska, A.; Errico, M.E. Gennaro gentile and grozdanov aeco-challenges of bio-based polymer composites. Materials 2009, 2, 911-925.

21. Wang, H.; Sun, X.Z.; Seib, P. Strengthening blends of poly(lactic acid) and starch with methylenediphenyl diisocyanate. J. Appl. Polym. Sci. 2001, 82, 1761-1767.

22. Ohkita, T.; Lee, S.H. Effect of aliphatic isocyanates (HDI and LDI) as a coupling agent on the properties of eco-composite from biodegradable polymers and corn starch. J. Adhes. Sci. Technol. 2004, 18, 905-924.

23. Teixeira, E.M.; Da Roz, A.L.; Carvalho, A.J.F.; Curvelo, A.A.S. The effect of glycerol/sugar/water and sugar/water mixtures on the plasticization of thermoplastic cassava starch. Carbohydr. Polym. 2007, 69, 619-624.

24. Rodriguez-Gonzalez, F.J.; Ramsay, B.A.; Favis, B.D. Rheological and thermal properties of thermoplastic starch with high glycerol content. Carbohydr. Polym. 2004, 58, 139-147.

25. Ma, X.F.; Yu, J.G.; Wan, J.J. Urea and ethanolamine as a mixed plasticizer for thermoplastic starch. Carbohydr. Polym. 2006, 64, 267-273.

26. Shi, R.; Zhang, Z.Z.; Liu, Q.Y.; Han, Y.M.; Zhang, L.Q.; Chen, D.F. Characterization of citric acid/glycerol co-plasticized thermoplastic starch prepared by melt blending. Carbohydr. Polym. 2007, 69, 748-755.

27. Jang, J.W.Y.; Shin, B.Y. Thermal properties and morphology of biodegradable PLA/starch Compatibilized Blends. Eng. Chem. 2007, 13, 457-464.

28. Wang, J.W.; Zhai, W.T.; Zheng, W.G. Poly(ethylene glycol) grafted starch introducing a novel interphase in poly(lactic acid)/poly(ethylene glycol)/starch ternary composite. J. Polym. Environ. 2012, 2, 528-539.

29. Xiong, Z.; Yang, Y.; Feng, J.X.; Zhang, X.; Zhang, C.Z.; Tang, Z.B. Preparation and characterization of poly(lactic acid)/starch composites toughened with epoxidized soybean oil. Carbohydr. Polym. 2013, 92, 810-816.

30. Acioli-Moura, R.; Sun, X.S. Thermal degradation and physical aging of poly(lactic acid) and its blends with starch ricardo. Polym. Eng. Sci. 2008, 48, 829-836.

31. Xiong, Z.; Zhang, L.S.; Ma, S.Q.; Yang, Y.; Zhang, C.Z.; Tang, Z.B.; Zhu, J. Effect of castor oil enrichment layer produced by reaction on the properties of PLA/HDI-g-starch blends. Carbohydr. Polym. 2013, 94, 235-243.

32. Poramacom, N.; Ungsuratana, A.O.; Ungsuratana, P.; Supavititpattana, P. Cassava production, prices and related policy in Thailand. Am. Int. J. Contemp. Res. 2013, 3, 43-51.

33. Tsou, C.H.; Hung, W.S.; Chen, J.C.; Huang, C.Y.; Wu, C.S.; Chiu, S.H.; Tsou, C.Y.; Chen, J.C.; Chu, C.K.; Hu, C.C.; et al. New composition of maleic-anhydride-grafted poly(lactic acid)/rice husk with methylenediphenyl diisocyanate. Mater. Sci. 2014, in press.

34. Zhao, Y.L.; Cai, Q.; Shuai, X.T.; Bei, J.Z.; Chen, C.F.; Xi, F. Synthesis and thermal properties of novel star-shaped poly(L-lactide)s with starburst PAMAM-OH dendrimer macroinitiator. Polymer 2002, 43, 5819-5825.

35. Kim, E.S.; Kim, B.C.; Kim, S.H. Structural effect of linear and star-shaped poly(L-lactic acid) on physical properties. J. Polym. Sci. Part B Polym. Phys. 2004, 42, 939-946. 
36. Liu, H.; Chen, F.; Liu, B.; Estep, G.; Zhang, J. Super toughened poly(lactic acid) ternary blends by simultaneous dynamic vulcanization and interfacial compatibilization. Macromolecules 2010, 43, 6058-6066.

37. Jiang, L.; Wolcott, M.P.; Zhang, J. Study of biodegradable polylactide/poly(butylene adipate-coterephthalate) blends. Biomacromolecules 2006, 7, 199-207.

38. Williams, G.I.; Wool, R.P. Composites from natural fibers and soy oil resins. Wool. Appl. Compos. Mater. 2000, 7, 421-432.

39. Natural Fibre: Plastics and Composites; Wallenberger, F.T., Weston, N.E., Eds.; Kluwer Academic Publishers: Dordrecht, The Netherlands, 2004.

40. Martin, P.; Maquet, C.; Legras, R.; Bailly, C.; Leemans, L.; van Gurp, M. Conjugated effects of the compatibilization and the dynamic vulcanization on the phase inversion behavior in poly(butylene terephthalate)/epoxide-containing rubber reactive polymer blends. Polymer 2004, 45, 5111-5125.

41. Martin, P.; Maquet, R.C.; Legras, C.; Bailly, L.; van Gurp Leemans, M. Particle-in-particle morphology in reactively compatibilized poly(butylene terephthalate)/epoxide-containing rubber blends. Polymer 2004, 45, 3277-3284.

42. Lim, J.S.; Park, K.I.; Chung, G.S.; Kim, J.H. Effect of composition ratio on the thermal and physical properties of semicrystalline PLA/PHB-HHx composites. Mater. Sci. Eng. 2013, 33, 2131-2137.

43. Gerard, T.; Budtova, T. Morphology and molten-state rheology of polylactide and polyhydroxyalkanoate blends. Eur. Polym. J. 2002, 48, 1110-1117.

44. Labrecque, L.V.; Dave, R.A.; Gross, R.A. Citrate esters as plasticizers for poly(lactic acid). J. Appl. Polym. Sci.1997, 66, 1507-1513.

45. Kulinski, Z.; Piorkowska, E.; Gadzinowska, K. Plasticization of poly(L-lactide) with poly(propylene glycol). Biomacromolecules 2006, 7, 2128-2135.

46. Ljungberg, N.; Wesslen, B. Preparation and properties of plasticized poly(lactic acid) films. Biomacromolecules 2005, 6, 1789-1796.

47. Ljungberg, N.; Andersson, T.; Wesslen, B. Film extrusion and film weldability of poly(lactic acid) plasticized with triacetine and tributyl citrate. J. Appl. Polym. Sci. 2003, 88, 3239-3247.

48. Martin, O.; Averous, L. Poly(lactic acid): Plasticization and properties of biodegradable multiphase systems. Polymer 2001, 42, 6209-6219.

49. Jacobsen, S.; Fritz, H.G. Plasticizing polylactide-the effect of different plasticizers on the mechanical properties. Polym. Eng. Sci. 1999, 39, 1303-1310.

50. Yeh, J.T.; Huang, C.Y.; Chai, W.L.; Chen, K.N. Plasticized properties of poly (lactic acid) and triacetine blends. J. Appl. Polym. Sci. 2009, 112, 2757-2763.

51. Baiardo, M.; Frisoni, G.; Scandola, M.; Michel, R.; Lips, D.; Ruffieux, K.; Wintermantel, E. Thermal and mechanical properties of plasticized poly(L-lactic acid). J. Appl. Polym. Sci. 2003, 90, 1731-1738.

52. Standard Test Method for Tensile Properties of Plastics. Available online: http://www.astm.org/ Standards/D638.htm (accessed on 31 July 2014).

(C) 2014 by the authors; licensee MDPI, Basel, Switzerland. This article is an open access article distributed under the terms and conditions of the Creative Commons Attribution license (http://creativecommons.org/licenses/by/3.0/). 